\title{
QUEEN'S
UNIVERSITY
BELFAST
}

\section{Long-term hip loading in unilateral total hip replacement patients is no different between limbs or compared to healthy controls at similar}

walking speeds

O'Connor, J. D., Rutherford, M., Bennett, D., Hill, J. C., Beverland, D. E., Dunne, N. J., \& Lennon, A. B. (2018). Long-term hip loading in unilateral total hip replacement patients is no different between limbs or compared to healthy controls at similar walking speeds. Journal of Biomechanics.

https://doi.org/10.1016/j.jbiomech.2018.07.033

\section{Published in:}

Journal of Biomechanics

\section{Document Version:}

Peer reviewed version

Queen's University Belfast - Research Portal:

Link to publication record in Queen's University Belfast Research Portal

\section{Publisher rights}

Copyright 2018 Elsevier.

This manuscript is distributed under a Creative Commons Attribution-NonCommercial-NoDerivs License

(https://creativecommons.org/licenses/by-nc-nd/4.0/), which permits distribution and reproduction for non-commercial purposes, provided the author and source are cited.

\section{General rights}

Copyright for the publications made accessible via the Queen's University Belfast Research Portal is retained by the author(s) and / or other copyright owners and it is a condition of accessing these publications that users recognise and abide by the legal requirements associated with these rights.

\section{Take down policy}

The Research Portal is Queen's institutional repository that provides access to Queen's research output. Every effort has been made to ensure that content in the Research Portal does not infringe any person's rights, or applicable UK laws. If you discover content in the

Research Portal that you believe breaches copyright or violates any law, please contact openaccess@qub.ac.uk. 
Original Article: Long-Term Hip Loading in Unilateral Total Hip Replacement Patients is no

Different between Limbs or Compared to Healthy Controls at Similar Walking Speeds

John D. O’Connor ${ }^{\mathrm{a}}$, Megan Rutherford ${ }^{\mathrm{a}}$, Damien Bennett ${ }^{\mathrm{b}}$, Janet C. Hill ${ }^{\mathrm{b}}$, David E. Beverland ${ }^{\mathrm{b}}$,

Nicholas J. Dunne ${ }^{\mathrm{c}-\mathrm{f}}$, Alex B. Lennon ${ }^{\mathrm{a}}$

a School of Mechanical and Aerospace Engineering, Queen's University Belfast, Belfast, UK

${ }^{\mathrm{b}}$ Primary Joint Unit, Musgrave Park Hospital, Belfast, UK

${ }^{\mathrm{c}}$ School of Mechanical \& Manufacturing Engineering, Dublin City University, Dublin, Ireland

${ }^{\mathrm{d}}$ Centre for Medical Engineering Research, School of Mechanical \& Manufacturing Engineering,

Dublin City University, Dublin, Ireland

${ }^{\mathrm{e}}$ Trinity Centre for Bioengineering, Trinity College Dublin, Dublin, Ireland

${ }^{\mathrm{f}}$ Queen's University Belfast, School of Pharmacy, Belfast, UK

Corresponding author: Dr Alex Lennon

\author{
School of Mechanical and Aerospace Engineering \\ Queen's University Belfast, BT9 5AH \\ United Kingdom \\ Email: a.lennon@qub.ac.uk
}

Word Count: Excluding references, cover page, abstract \& figure captions - 2,993 words Abstract -245 words (1)

(1)

Keywords: hip contact forces, musculoskeletal modelling, total hip replacement 


\section{Abstract}

Variation in hip joint contact forces directly influences the performance of total hip replacements (THRs). Measurement and calculation of contact forces in THR patients has been limited by small sample sizes, wide variation in patient and surgical factors, and short-term follow-up. This study hypothesised that, at long-term follow-up, unilateral THR patients have similar calculated hip

31 contact forces compared to controls walking at similar (self-selected) speeds and, in contrast, THR patients walking at slower (self-selected) speeds have reduced hip contact forces. It was further hypothesised that there is no difference in calculated hip contact forces between operated and nonoperated limbs at long-term follow-up for both faster and slower patients. Gait analysis data for THR patients walking at faster (walking speed: $1.29 \pm 0.12 \mathrm{~m} / \mathrm{s} ; \mathrm{n}=11$ ) and slower (walking speed: $0.72 \pm 0.09 \mathrm{~m} / \mathrm{s} ; \mathrm{n}=11$ ) speeds were used. Healthy subjects constituted the control group (walking speed: $1.36 \pm 0.12 \mathrm{~m} / \mathrm{s} ; \mathrm{n}=10$ ). Hip contact forces were calculated using static optimisation. There was no significant difference ( $p>0.31$ ) in hip contact forces between faster and control groups.

39 Conversely, force was reduced at heel strike by $19 \%(\mathrm{p}=0.002)$, toe-off by $31 \%(\mathrm{p}<0.001)$ and increased at mid-stance by $15 \%(\mathrm{p}=0.02)$ for the slower group compared to controls. There were no

41 differences between operated and non-operated limbs for the slower group or the faster group, suggesting good biomechanical recovery at long-term follow-up. Loading, at different walking speeds, presented here can improve the relevance of preclinical testing methods. 


\section{Introduction}

Total hip replacement (THR) is a well-established and largely successful orthopaedic procedure, which is primarily employed to treat end-stage osteoarthritis (UK National Joint Registry, 2017). The UK National Joint Registry reports 13-year revision rates of less than $7 \%$ for the majority of bearing types (UK National Joint Registry, 2017). Although hip joint contact forces (HCFs) are related to both short-term (e.g. implant micromotion) and long-term THR failure mechanisms (e.g. peri-prosthetic bone remodelling) (Sumner, 2015), direct measurement has only been possible in small samples of disparate patients using instrumented implants (Bergmann et al., 2001; Davy et al., 1988; Rydell, 1966). Musculoskeletal models have been used to calculate HCFs from three dimensional motion capture data and ground reaction forces, with good agreement to instrumented implant measurements (Heller et al., 2001; Modenese et al., 2011; Modenese and Phillips, 2012; Stansfield et al., 2003). Nevertheless, musculoskeletal modelling of HCFs in THR patients has been limited by small sample sizes, short-term follow-up, and wide variation in patient, surgical, and implant factors (Foucher et al., 2009; Li et al., 2014; Stansfield and Nicol, 2002; Wesseling et al., 2016a).

Recently, musculoskeletal modelling of healthy subjects reported that walking speed has a considerable impact on predicted HCFs (Giarmatzis et al., 2017, 2015). Unfortunately, studies reporting HCFs in THR patients have not controlled for walking speed or have been confined to a few patients at short-term follow-up (Bergmann et al., 1993; Heller et al., 2001; Li et al., 2014; Modenese and Phillips, 2012; Stansfield et al., 2003; Wesseling et al., 2016a). It is unclear whether differences observed (e.g. lower HCFs compared to controls) in THR patients relative to healthy subjects are due to walking speed, variable or short-term follow-up, or other surgical outcomes.

Hip moments in THR patients have been reported to be significantly altered at both short-term (Beaulieu et al., 2010) and long-term follow-up (Bennett et al., 2017) compared to controls. At short-term follow-up, differences in HCFs for THR patients compared to controls have also been found across a range of surgical approaches, even with similar walking speeds (Wesseling et al., 
70 2016b). When comparing between limbs, differences have been observed in hip moments between

71 operated and contralateral limbs (Foucher and Wimmer, 2012). However, Li et al. (2014) found no

72 difference in HCFs between limbs 12 months after unilateral THR. To the authors' knowledge, no

73 long-term study has been conducted comparing THR patients' HCFs at different speeds to controls

74 and between limbs.

75 This study hypothesised that, at long-term follow-up, unilateral THR patients have similar

76 calculated HCFs compared to controls walking at similar (self-selected) speeds and, in contrast,

77 THR patients walking at slower (self-selected) speeds have reduced HCFs. It was further

78 hypothesised that there is no difference in calculated HCFs between operated and non-operated

79 limbs at long-term follow-up for both faster and slower patients. 


\subsection{Patient and control data}

All patients received unilateral THRs in Musgrave Park Hospital (Belfast, UK) under the senior author (DEB) using a posterior approach with the same cemented implants (Orthogenesis custom X-press femoral implant and Elite acetabular implant, DePuy International, Leeds, UK). All had a $28 \mathrm{~mm}$ femoral head articulating with an ultra-high molecular weight polyethylene acetabular implant.

Three dimensional gait analysis was undertaken using retroreflective markers placed according to the Helen Hayes marker set (Kadaba et al., 1990). At least three walking trials were performed along a central walkway ( $8-10 \mathrm{~m}$ length) and a single representative trial was used for analysis. All patients and control subjects walked bare foot. Data was captured at $120 \mathrm{~Hz}$ using a six-camera Vicon 612 system and patients walked at self-selected speed. Patients were stratified by walking speed and the 11 slowest and 11 fastest patients (out of a total of 134 patients) with sufficient force plate data for operated and non-operated limbs were used for musculoskeletal analysis. Force plate data was collected at $120 \mathrm{~Hz}$ using two force plates (AMTI, Watertown, MA) and assessed visually using Mokka (Version 0.6, BioMechanical Toolkit) (Barre and Armand, 2014). Force plates were fully concealed and integrated into the floor covering. To avoid targeting, patients were not told of their position and instructed to walk at their normal walking speed. Patients were studied 10 years post-operatively: follow-up ranged from 9.72 to 10.41 years for slower patients and 9.13 to 10.18 years for the faster cohort. Three-dimensional gait data from 10 healthy elderly controls was also used for musculoskeletal analysis. Controls and THR groups' age ranges and body mass index (BMI) are presented in Table 1. Ethical approval was obtained from the local ethics committee (Queen's University Belfast, Faculty of Medicine, Research Ethics Committee, Reference number: 253/02). 


\subsection{Musculoskeletal modelling}

105 A lower extremity model, "gait2392”, with 12 segments, 23 degrees of freedom and Hill-type 106 models of 92 muscle-tendon compartments was used to analyse gait with a standard static optimisation workflow in OpenSim 3.3 (Stanford University, CA, USA) (Delp et al., 2007, 1990). Lumbar extension, lumbar bending, lumbar rotation, metatarsophalangeal and subtalar joints were fixed in anatomical neutral positions for all analyses. A zero-lag low-pass filter with a cut-off

110 frequency of $6 \mathrm{~Hz}$ was applied to ground reaction forces and kinematics (Mantoan et al., 2015).

111 Isotropic scaling of the generic model segments was performed based on markers placed on bony

112 landmarks of the subject with the exception of the pelvis, where the laboratory-measured distance 113 between the left and right anterior superior iliac spines was used (Figure 1).

114 Inverse kinematics and inverse dynamics were performed to calculate joint angles and moments 115 respectively. Static optimisation was executed to estimate the muscle activations and forces. The 116 objective function for static optimisation minimised the sum of the muscle activations (defined as 117 the ratio of predicted force relative to maximum isometric force for the muscle) squared based on a 118 study showing that this criterion produces realistic HCFs and muscle activation patterns relative to 119 instrumented implant and EMG data (Modenese et al., 2011). In accordance with OpenSim best 120 practice, reserve actuators were added to the joint between the pelvis and the ground to account for 121 dynamic inconsistencies caused by errors in the model estimations of the subject's inertial 122 parameters and geometry as well as marker placement/tracking inaccuracies. Force-length-velocity 123 relationships were not used for the muscle models in this study as they have been shown not to 124 affect the calculation of HCFs for level walking (Anderson and Pandy, 2001). Finally, a joint 125 reaction analysis was performed in OpenSim in order to calculate the resultant hip force, i.e. HCF. 126 All HCFs were subsequently normalised to body weight (BW) and the moments were divided by 127 body mass in kilograms $(\mathrm{Nm} / \mathrm{kg})$. 


\subsection{Data analysis and statistics}

129 The start and end of the gait cycle were identified and 100-point splines were fitted to the HCFs and 130 hip moments for both sides in MATLAB (2015b, TheMathWorks, Inc., MA, USA). These points 131 were used to create ensemble average curves for the control, slower patient, and faster patient 132 groups. Ensembles curves were also created for comparison between operated and non-operated 133 limbs in both the faster and slower patient groups. Peaks in HCF at heel strike, mid-stance, and toe134 off were identified for quantitative statistical analysis. These points within the gait cycle were also 135 used to compare hip adduction moments, while hip flexion moments were compared using 136 maximum and minimum values of a complete gait cycle and hip rotation moment was compared 137 using only the maximum value. Differences between HCFs and moments for operated and non138 operated peaks were tested using the paired Wilcoxon Signed Rank-Sum Test as the data were not 139 normally distributed. Control subjects were compared (by hip kinematics, HCFs and hip moments) 140 to the speed-stratified groups with a Wilcoxon Rank-Sum Test using a Bonferroni correction for 141 multiple comparisons. In cases where a Bonferroni correction was used, the p-value has been 142 multiplied by the number of comparisons so that the interpretation is the same for all data, i.e. $143 \mathrm{p}<0.05$ is significant. All statistical analysis was performed using R (Version 3.4.0) (R Core Team, 144 2017).

\section{Results}

146 Maximum hip extension was significantly $(\mathrm{p}<0.001)$ reduced in slower THR patients compared to 147 controls (Figure 2; Table 2). Similarly, hip adduction range was significantly lower $(\mathrm{p}<0.01)$ for 148 both THR groups (i.e. slower and faster) compared to controls (Figure 2; Table 2). Overall, hip 149 moments tended to be reduced in the THR groups compared with the control group (Figure 2; Table 150 3). In particular, the slower group had lower peak extension $(\mathrm{p}<0.001$; Figure 2$)$ and internal 151 rotation moments ( $\mathrm{p}=0.002$; Figure 2$)$ when compared to control subjects; this trend was matched 
152 by the faster patients for extension ( $\mathrm{p}=0.002$; Figure 2$)$ and internal rotation moments $(\mathrm{p}=0.03$;

153 Figure 2). The abduction moment showed a similar trend to HCFs, i.e. distinct double peak for 154 faster and control groups while slower patients showed a higher mid-stance moment $(\mathrm{p}<0.05)$,

155 similar in magnitude to the heel-strike and toe-off peaks. In terms of magnitude, the faster THR 156 patients' moments were more comparable to the control group than the slower THR group.

Ensemble averaged HCFs of faster THR patients and control subjects showed a distinct double peak profile whereas slower THR patients exhibited lower HCFs and a plateau during stance phase (Figure 3). There were significant differences in HCFs between slower THR subjects and control subjects at heel-strike $(\mathrm{p}=0.002)$, mid-stance $(\mathrm{p}=0.02)$ and toe-off $(\mathrm{p}<0.001)($ Table 4 and Figure 3$)$.

161 Conversely, there was no statistical difference $(\mathrm{p}>0.31)$ between these forces in faster THR patients 162 compared to controls (Figure 3). There were no significant differences between operated and non163 operated limb HCFs at heel-strike, mid-stance, or toe-off ( $p>0.10)$ for either the faster or slower 164 patient groups (Figure 4).

\section{Discussion}

The first hypothesis of this investigation was that calculated HCFs in THR patients at long-term follow-up are comparable to healthy control subjects at similar walking speeds and HCFs of slower patients are significantly reduced. We also hypothesised that HCFs of operated and non-operated limbs in THR patients were not significantly different at long-term follow-up. The results supported both hypotheses. Slower patients showed a less dynamic HCF profile whereas both faster and 171 control groups showed increased contact forces at the beginning and end of stance phase and lower contact force at mid-stance. There was no difference in hip contact forces throughout the gait cycle between operated and non-operated limbs in either the faster or slower groups. instrumented implants) at similar walking speeds. For example, instrumented implant measurements 
group speed of $0.72 \pm 0.09 \mathrm{~m} / \mathrm{s}$ ) averaged 3.5 BW for peak HCF compared to $2.98 \mathrm{BW}$ in our study. Predicted HCFs, using a similar musculoskeletal modelling approach, for elderly healthy subjects walking at $0.83 \mathrm{~m} / \mathrm{s}$ also show good agreement with our findings at low walking speeds, peaking at 3.3 BW (Giarmatzis et al., 2017). At a walking speed of $1.38 \mathrm{~m} / \mathrm{s}$, and for elderly female patients, Giarmatzis et al. (2017) estimated a mean hip joint loading at the first peak of 4.3 BW and 4.6 BW at the second peak, while Weinhandl et al. (2017) predicted peaks of $3.39 \pm 0.45 \mathrm{BW}$ and $4.61 \pm$ $0.55 \mathrm{BW}$ for a cohort of five male and five female young, healthy subjects walking at $1.34 \pm 0.07$ $\mathrm{m} / \mathrm{s}$. The values presented here are similar at $3.5 \pm 0.6 \mathrm{BW}$ and $4.5 \pm 0.9 \mathrm{BW}$.

In the studies described above, excluding Weinhandl et al. (2017), subject speed was controlled using a treadmill rather than being self-selected. Similar HCFs have been predicted for disparate cohorts when walking speed was matched, e.g. Giarmatzis et al. (2017) showed very similar force profiles between young and old groups at matched walking speeds between $0.83 \mathrm{~m} / \mathrm{s}$ and $1.94 \mathrm{~m} / \mathrm{s}$. Walking speed in our study was self-selected and patients were not tested on a treadmill. Walking speed is related to physical and mental function (Peel et al., 2013) with faster patients generally expected to have better function. Consequently, our study is likely capturing the best functioning THR patients in the faster cohort and the worst in the slower group.

A previous study (Li et al., 2014) using different musculoskeletal modelling methodology showed similar trends but altered magnitudes: Li et al. (2014) presented HCFs for a relatively young control group (average age: 44.97 years) walking at $1.44 \mathrm{~m} / \mathrm{s}(1.39-1.50 \mathrm{~m} / \mathrm{s})$ and found a considerably lower mean toe-off peak of $3.67 \mathrm{BW}$ compared to controls in this study and the publications by Giarmatzis et al. (2015) and Weinhandl et al. (2017) on healthy subjects. These differences are most likely due to the methodological approaches, with Li et al. (2014) opting for the Anybody software (AnyBody Technology, Aalborg, Denmark) and model while the other studies, including the current, use OpenSim with the "gait2392" model. These two modelling approaches have shown altered muscle force estimations in a comparative study (Trinler et al., 
2017), which can be a result of separate scaling and mathematical optimisation processes in each software.

With regard to comparisons between operated and non-operated limbs, the findings in this investigation are in agreement with previous works at short-term follow-up (Beaulieu et al., 2010; Benedetti et al., 2010; Li et al., 2015, 2014). The close matching of hip contact force profiles between operated and non-operated limbs suggests good biomechanical recovery at long-term follow-up. The absence of difference in HCFs between operated and non-operated limbs for both faster and slower patients suggests symmetrical biomechanical recovery is achieved, which is independent of walking speed. Foucher and Wimmer (2012) report an increased abduction moment in the non-operated hip preoperatively compared to speed-matched controls, with no improvement up to 1 year following THR. In contrast, we found no significant difference in hip abduction moment between faster patients compared to normal subjects and significantly lower hip internal rotation and extension moments, which may be due to the longer period of recovery (Figure 2). Strengths of this study include control of possible confounding surgical and patient factors. In addition, many previous works have assessed HCFs shortly after surgery when patients have variable levels of recovery whereas we report HCFs at long-term follow-up (Bergmann et al., 2001; Heller et al., 2001; Li et al., 2014; Stansfield et al., 2003; Stansfield and Nicol, 2002).

Notwithstanding these strengths, there were several important potential limitations to this study. Firstly, gait kinematics, kinetics, and walking speed have been shown to be age-related (Bennett et al., 2017, 2008), and there was an age difference between the slower THR and control groups in this study. However, Giarmatzis et al. (2017) have shown that walking speed difference would be expected to influence kinetics independent of age. Secondly, patients were stratified by walking speed from a larger dataset (Bennett et al., 2008), meaning patients walking at mid-range speeds were not included. In our opinion, assessing the extremes of walking speed has the advantage of establishing more useful ranges for preclinical testing design that are relevant to the increasing volume of THR procedures being performed (UK National Joint Registry, 2017). Lastly, 
while the sample sizes in this study are based on previous works with similar aims (Foucher et al., 2009; Li et al., 2014; Stansfield and Nicol, 2002; Wesseling et al., 2016a), future studies involving larger sample sizes would likely add to the findings presented here.

Limitations in the modelling aspects of this investigation include isotropic scaling of a generic musculoskeletal model based on the location of gait markers, as used here and in similar studies (Giarmatzis et al., 2015; Weinhandl et al., 2017). This may be susceptible to misplacing the joint centres and is particularly pertinent since previous validation studies have used CT and X-ray derived joint centres (Modenese et al., 2011; Stansfield et al., 2003). This has increased relevance in THR patients as the location of the hip joint centre is often shifted following THR surgery (Bonnin et al., 2012). Previous studies suggest that the location of the joint centre may be improved through the use of medical imaging (Kainz et al., 2017; Lenaerts et al., 2009) or a functional method (Leardini et al., 1999). Lenaerts et al. (2009) compared CT measurements to a linear scaled generic model, finding an anterior and proximal shift of the hip joint centre location of $30 \mathrm{~mm}$ and $20 \mathrm{~mm}$ respectively; this did not cause a significant effect on the magnitude of HCFs but did influence the orientation of the force. Future investigations examining the accuracy of hip joint centre location in THR patients would help in the interpretation of this work.

The findings of this study have important implications for preclinical testing of THR implants and patient recovery. Firstly, there were considerable differences in HCFs (both in force profile shape and magnitude of loading) between slower and faster THR patients suggesting preclinical simulation studies should include this loading variability. Secondly, this study shows that selfselected walking speed is associated with contact force in the hip joint and should therefore influence study design when comparing THR patients to controls. Thirdly, HCFs (and moments, Appendix 1) are similar between operated and non-operated limbs at long-term follow-up suggesting patients have good biomechanical recovery.

In conclusion, the hypothesis that there is no difference between healthy control subject HCFs and THR patient HCFs at similar walking speeds was supported by this study. We also showed 
254 there to be large differences between slower THR patients and both control and faster groups. The 255 difference between a faster and slower THR patient, in terms of HCF, is substantial and is relevant 256 to both computational and lab-based preclinical testing methods and many biomechanical failure 257 mechanisms of THR. In addition, we found contact forces to be no different between the operated 258 and non-operated hips at both faster and slower walking speeds. This equalisation may be indicative 259 of the longer recovery period studied here.

260 Acknowledgements

261 Nicholas Dunne, Alex Lennon and John O'Connor report grants from Belfast Arthroplasty Research 262 Trust and from Department of Employment and Learning, Northern Ireland. Megan Rutherford 263 reports grants from Belfast Arthroplasty Research Trust related to the current study.

\section{Conflict of interest}

265 The Belfast Arthroplasty Research Trust has received funding from DePuy Synthes and Zimmer 266 Biomet but not directly for this work. 
Anderson, F.C., Pandy, M.G., 2001. Static and dynamic optimization solutions for gait are practically equivalent. J. Biomech. 34, 153-161.

Barre, A., Armand, S., 2014. Biomechanical ToolKit: Open-source framework to visualize and process biomechanical data. Comput. Methods Programs Biomed. 114, 80-87.

Beaulieu, M.L., Lamontagne, M., Beaulé, P.E., 2010. Lower limb biomechanics during gait do not return to normal following total hip arthroplasty. Gait Posture 32, 269-73.

Benedetti, M.G., Catani, F., Benedetti, E., Berti, L., Di Gioia, A., Giannini, S., 2010. To what extent does leg length discrepancy impair motor activity in patients after total hip arthroplasty? Int.

Bennett, D., Ryan, P., O’Brien, S., Beverland, D.E., 2017. Gait kinetics of total hip replacement patients-A large scale, long-term follow-up study. Gait Posture 53, 173-178.

Bergmann, G., Deuretzbacher, G., Heller, M., Graichen, F., Rohlmann, A., Strauss, J., Duda, G.N., 2001. Hip contact forces and gait patterns from routine activities. J. Biomech. 34, 859-871.

Bergmann, G., Graichen, F., Rohlmann, A., 1993. Hip joint loading during walking and running, measured in two patients. J. Biomech. 26, 969-990.

Bonnin, M.P., Archbold, P.H., Basiglini, L., Fessy, M.H., Beverland, D.E., 2012. Do we medialise the hip centre of rotation in total hip arthroplasty? Influence of acetabular offset and surgical technique. Hip Int. 22, 371-378.

Davy, D.T., Kotzar, G.M., Brown, R.H., Heiple, K.G., Goldberg, V.M., Heiple, K.G.J., Berilla, J., Burstein, A.H., 1988. Telemetric force measurements across the hip after total arthroplasty. J. Bone Joint Surg. Am. 70, 45-50.

Delp, S.L., Anderson, F.C., Arnold, A.S., Loan, P., Habib, A., John, C.T., Guendelman, E., Thelen, 
D.G., 2007. OpenSim: Open-Source Software to Create and Analyze Dynamic Simulations of Movement. Biomed. Eng. IEEE Trans. 54, 1940-1950.

Delp, S.L., Loan, J.P., Hoy, M.G., Zajac, F.E., Topp, E.L., Rosen, J.M., 1990. An interactive graphics-based model of the lower extremity to study orthopaedic surgical procedures. IEEE Trans. Biomed. Eng. 37, 757-767.

Foucher, K.C., Hurwitz, D.E., Wimmer, M.A., 2009. Relative importance of gait vs. joint positioning on hip contact forces after total hip replacement. J. Orthop. Res. 27, 1576-1582.

Foucher, K.C., Wimmer, M.A., 2012. Contralateral hip and knee gait biomechanics are unchanged

Giarmatzis, G., Jonkers, I., Baggen, R., Verschueren, S., 2017. Less hip joint loading only during running rather than walking in elderly compared to young adults. Gait Posture 53, 155-161.

Giarmatzis, G., Jonkers, I., Wesseling, M., Van Rossom, S., Verschueren, S., 2015. Loading of Hip Measured by Hip Contact Forces at Different Speeds of Walking and Running. J. Bone Miner. Res. 30, 1431-1440.

Heller, M.., Bergmann, G., Deuretzbacher, G., Dürselen, L., Pohl, M., Claes, L., Haas, N.., Duda, G.., 2001. Musculo-skeletal loading conditions at the hip during walking and stair climbing. J. Biomech. 34, 883-893.

Kadaba, M.P., Ramakrishnan, H.K., Wootten, M.E., 1990. Measurement of lower extremity kinematics during level walking. J. Orthop. Res. 8, 383-392.

Kainz, H., Hoang, H., Stockton, C., Boyd, R.R., Lloyd, D.G., Carty, C.P., 2017. Accuracy and Reliability of Marker Based Approaches to Scale the Pelvis, Thigh and Shank Segments in Musculoskeletal Models. J. Appl. Biomech. 33, 1-21.

Leardini, A., Cappozzo, A., Catani, F., Toksvig-Larsen, S., Petitto, A., Sforza, V., Cassanelli, G., Giannini, S., 1999. Validation of a functional method for the estimation of hip joint centre location. J. Biomech. 32, 99-103.

Lenaerts, G., Bartels, W., Gelaude, F., Mulier, M., Spaepen, A., Van der Perre, G., Jonkers, I., 2009. 
Subject-specific hip geometry and hip joint centre location affects calculated contact forces at the hip during gait. J. Biomech. 42, 1246-1251.

Li, J., McWilliams, A.B., Jin, Z., Fisher, J., Stone, M.H., Redmond, A.C., Stewart, T.D., 2015. Unilateral total hip replacement patients with symptomatic leg length inequality have abnormal hip biomechanics during walking. Clin. Biomech. 30, 513-519.

Li, J., Redmond, A.C., Jin, Z., Fisher, J., Stone, M.H., Stewart, T.D., 2014. Hip contact forces in asymptomatic total hip replacement patients differ from normal healthy individuals: Implications for preclinical testing. Clin. Biomech. (Bristol, Avon) 29, 747-51.

Mantoan, A., Pizzolato, C., Sartori, M., Sawacha, Z., Cobelli, C., Reggiani, M., 2015. MOtoNMS: A MATLAB toolbox to process motion data for neuromusculoskeletal modeling and simulation. Source Code Biol. Med. 10, 12.

Modenese, L., Phillips, A.T.M., 2012. Prediction of hip contact forces and muscle activations during walking at different speeds. Multibody Syst. Dyn. 28, 157-168.

Modenese, L., Phillips, A.T.M., Bull, A.M.J., 2011. An open source lower limb model: Hip joint validation. J. Biomech. 44, 2185-2193.

Peel, N.M., Kuys, S.S., Klein, K., 2013. Gait Speed as a Measure in Geriatric Assessment in Clinical Settings: A Systematic Review. Journals Gerontol. Ser. A 68, 39-46.

R Core Team, 2017. R: A Language and Environment for Statistical Computing, R Foundation for Statistical Computing, Vienna, Austria. https://www.r-project.org/.

Rydell, N.W., 1966. Forces acting on the femoral head-prosthesis. A study on strain gauge supplied prostheses in living persons. Acta Orthop. Scand. 37, Suppl 88:1-132.

Stansfield, B.W., Nicol, A.C., 2002. Hip joint contact forces in normal subjects and subjects with total hip prostheses: walking and stair and ramp negotiation. Clin. Biomech. 17, 130-139.

Stansfield, B.W., Nicol, A.C., Paul, J.P., Kelly, I.G., Graichen, F., Bergmann, G., 2003. Direct comparison of calculated hip joint contact forces with those measured using instrumented implants. An evaluation of a three-dimensional mathematical model of the lower limb. J. 
Biomech. 36, 929-936.

347 Sumner, D.R., 2015. Long-term implant fixation and stress-shielding in total hip replacement. J. $348 \quad$ Biomech. 48, 797-800.

349 Trinler, U., Alexander, N., Schwameder, H., Baker, R., 2017. MUSCLE FORCE ESTIMATION IN CLINICAL BIOMECHANICS: ANYBODY VS OPENSIM. In: 35th Conference of the International Society of Biomechanics in Sports. Cologne, Germany.

UK National Joint Registry, 2017. 14th Annual Report; Accessed 24-Oct-2017; http://www.njrcentre.org.uk.

354 Weinhandl, J.T., Irmischer, B.S., Sievert, Z.A., 2017. Effects of Gait Speed of Femoroacetabular Joint Forces. Appl. Bionics Biomech. 2017.

356 Wesseling, M., De Groote, F., Meyer, C., Corten, K., Simon, J.-P., Desloovere, K., Jonkers, I., $2016 a$. Subject-specific musculoskeletal modelling in patients before and after total hip arthroplasty. Comput. Methods Biomech. Biomed. Engin. 5842, 1-9.

359 Wesseling, M., Meyer, C., Corten, K., Simon, J.-P.P., Desloovere, K., Jonkers, I., 2016b. Does 360 surgical approach or prosthesis type affect hip joint loading one year after surgery? Gait Posture $44,74-82$. 
1 Table 1: Subject details for walking speed stratified groups; data is presented as mean \pm standard deviation

\begin{tabular}{ccccccc}
\hline Group & $\begin{array}{c}\text { Number of } \\
\text { Subjects }\end{array}$ & $\begin{array}{c}\text { Walking } \\
\text { Speed }(\mathrm{m} / \mathrm{s})\end{array}$ & Age (Years) & $\begin{array}{c}\text { BMI } \\
\left(\mathrm{kg} / \mathrm{m}^{2}\right)\end{array}$ & $\begin{array}{c}\text { Years to } \\
\text { Review }\end{array}$ & $\begin{array}{c}\text { Gender } \\
(\mathrm{M}: \mathrm{F})\end{array}$ \\
\hline Slower & 11 & $0.72 \pm 0.09$ & $74.18 \pm 7.21$ & $29.81 \pm 4.99$ & $10.00 \pm 0.20$ & $8: 3$ \\
Faster & 11 & $1.29 \pm 0.12$ & $70.56 \pm 4.88$ & $25.34 \pm 3.51$ & $9.76 \pm 0.30$ & $6: 5$ \\
Control & 10 & $1.36 \pm 0.12$ & $64.00 \pm 3.60$ & $26.22 \pm 3.01$ & N/A & $6: 4$
\end{tabular}


1 Table 2: Kinematics comparison between slower THR, faster THR and controls. Data is presented as mean \pm standard deviation.

$2 * * *=\mathbf{p}<0.001, * *=\mathbf{p}<0.01$ and $*=\mathbf{p}<0.05$ for differences between THR groups and control group only.

\begin{tabular}{lccc}
\hline & $\begin{array}{c}\text { Maximum hip } \\
\text { extension }\left(^{\circ}\right)\end{array}$ & $\begin{array}{c}\text { Hip } \\
\text { Adduction } \\
\text { range }\left(^{\circ}\right)\end{array}$ & $\begin{array}{c}\text { Hip rotation } \\
\text { range }\left(^{\circ}\right)\end{array}$ \\
\hline Slower & $-2.8 \pm 11.1^{* * *}$ & $8.0 \pm 4.1^{* * *}$ & $18.6 \pm 6.8$ \\
Faster & $-15.5 \pm 7.5$ & $10.9 \pm 3.3^{* *}$ & $23.0 \pm 6.7$ \\
Control & $-19.4 \pm 6.1$ & $13.8 \pm 2.3$ & $20.6 \pm 6.4$
\end{tabular}


1 Table 3: Moments comparison between slower THR, faster THR and controls. Data is presented as mean \pm standard deviation.

$2 * * *=\mathbf{p}<0.001, * *=\mathbf{p}<0.01$ and $*=\mathbf{p}<0.05$ for differences between THR groups and control group only.

\begin{tabular}{ccccccc}
\hline & $\begin{array}{c}\text { Max. flexion } \\
\text { moment }(\mathrm{Nm} / \mathrm{kg})\end{array}$ & $\begin{array}{c}\text { Max. extension } \\
\text { moment }(\mathrm{Nm} / \mathrm{Kg})\end{array}$ & $\begin{array}{c}\text { HS abduction } \\
\text { moment }(\mathrm{Nm} / \mathrm{kg})\end{array}$ & $\begin{array}{c}\text { MS abduction } \\
\text { moment }(\mathrm{Nm} / \mathrm{kg})\end{array}$ & $\begin{array}{c}\text { TO abduction } \\
\mathrm{moment}(\mathrm{Nm} / \mathrm{kg})\end{array} \begin{array}{c}\text { Maximum internal } \\
\text { rotation moment } \\
(\mathrm{Nm} / \mathrm{kg})\end{array}$ \\
\hline Slower & $0.33 \pm 0.11^{* * *}$ & $-0.63 \pm 0.26$ & $-0.64 \pm 0.18^{*}$ & $-0.60 \pm 0.15^{* *}$ & $-0.68 \pm 0.16$ & $0.11 \pm 0.07 * *$ \\
Faster & $0.59 \pm 0.10^{* *}$ & $-0.82 \pm 0.20$ & $-0.76 \pm 0.18$ & $-0.50 \pm 0.15$ & $-0.74 \pm 0.16$ & $0.13 \pm 0.07 *$ \\
Control & $0.76 \pm 0.18$ & $-0.83 \pm 0.25$ & $-0.82 \pm 0.18$ & $-0.44 \pm 0.14$ & $-0.76 \pm 0.16$ & $0.17 \pm 0.07$
\end{tabular}


1 Table 4: Hip contact forces for all groups; data is presented as mean \pm standard deviation. "slower" and "faster" groups are an average

2 of the operated and non-operated hips. $* * *=\mathbf{p}<0.001, * *=\mathbf{p}<0.01$ and $*=\mathbf{p}<0.05$ for differences between THR groups and control group

3 only for slower, faster and control groups. No statistical differences were evident between operated and non-operated hips.

\begin{tabular}{cccc}
\hline Group & Heel-strike force $(\mathrm{BW})$ & Mid-stance force $(\mathrm{BW})$ & $\begin{array}{c}\text { Toe-off } \\
\text { force }(\mathrm{BW})\end{array}$ \\
\hline Slower & $2.98 \pm 0.67 * *$ & $2.70 \pm 0.63 *$ & $3.18 \pm 0.71^{* * *}$ \\
Faster & $3.43 \pm 0.62$ & $2.35 \pm 0.57$ & $4.49 \pm 0.94$ \\
Control & $3.79 \pm 0.71$ & $2.17 \pm 0.54$ & $4.92 \pm 0.93$ \\
Slower - Operated & $3.08 \pm 0.62$ & $2.73 \pm 0.68$ & $3.24 \pm 0.74$ \\
Slower - Non-Operated & $2.89 \pm 0.68$ & $2.67 \pm 0.55$ & $3.13 \pm 0.68$ \\
Faster - Operated & $3.22 \pm 0.62$ & $2.25 \pm 0.58$ & $4.07 \pm 0.64$ \\
Faster - Non-Operated & $3.63 \pm 0.53$ & $2.44 \pm 0.53$ & $4.91 \pm 0.96$ \\
\hline
\end{tabular}




\section{Isotropic scaling}

Scale segments based on static gait trial

Scale factor is ratio of distance between two virtual $\left(\mathrm{D}_{\mathrm{V}}\right)$ and two experimental markers $\left(D_{E}\right)$

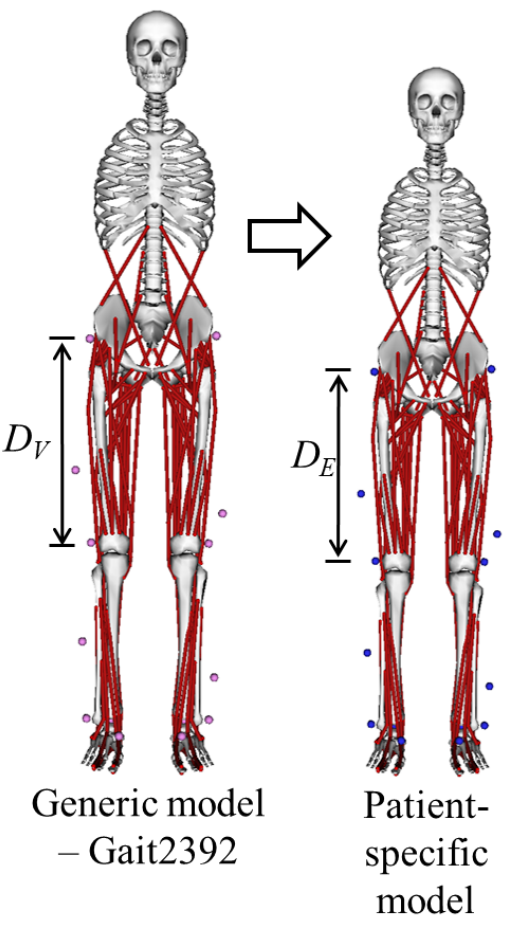

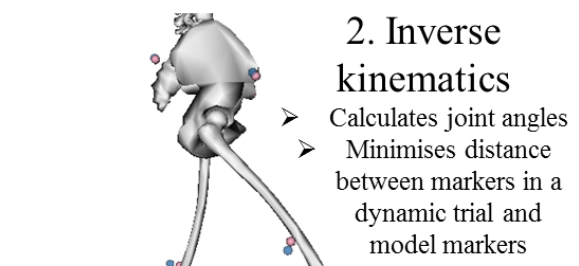

model markers
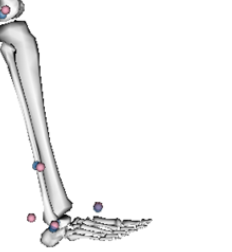

Inverse dynamics $>$ Calculates joint moments from model geometry, inertial parameters, segment centres of mass and the ground reaction forces

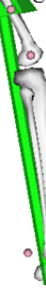

4. Static optimisation

$>$ Calculates muscle activations and hence forces

$>$ Sum of squared activations is the objective function

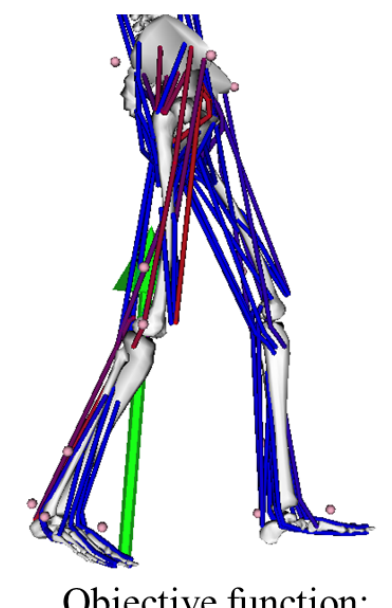

Objective function:

$J\left(F_{i}\right)=\sum_{i=1}^{n}\left(\frac{F_{i}}{F_{\text {isomax }, i}}\right)^{2}$

2 Figure 1: Overview of the workflow for musculoskeletal modelling. In the objective function $J, n$ is

3 the number of muscles in the model, $F_{\mathrm{i}}$ is the force of the $i_{\text {th }}$ muscle and $F_{\text {isomax,i }}$ is the maximum

4 isometric force of the muscle. 


\section{Kinematics Moments}
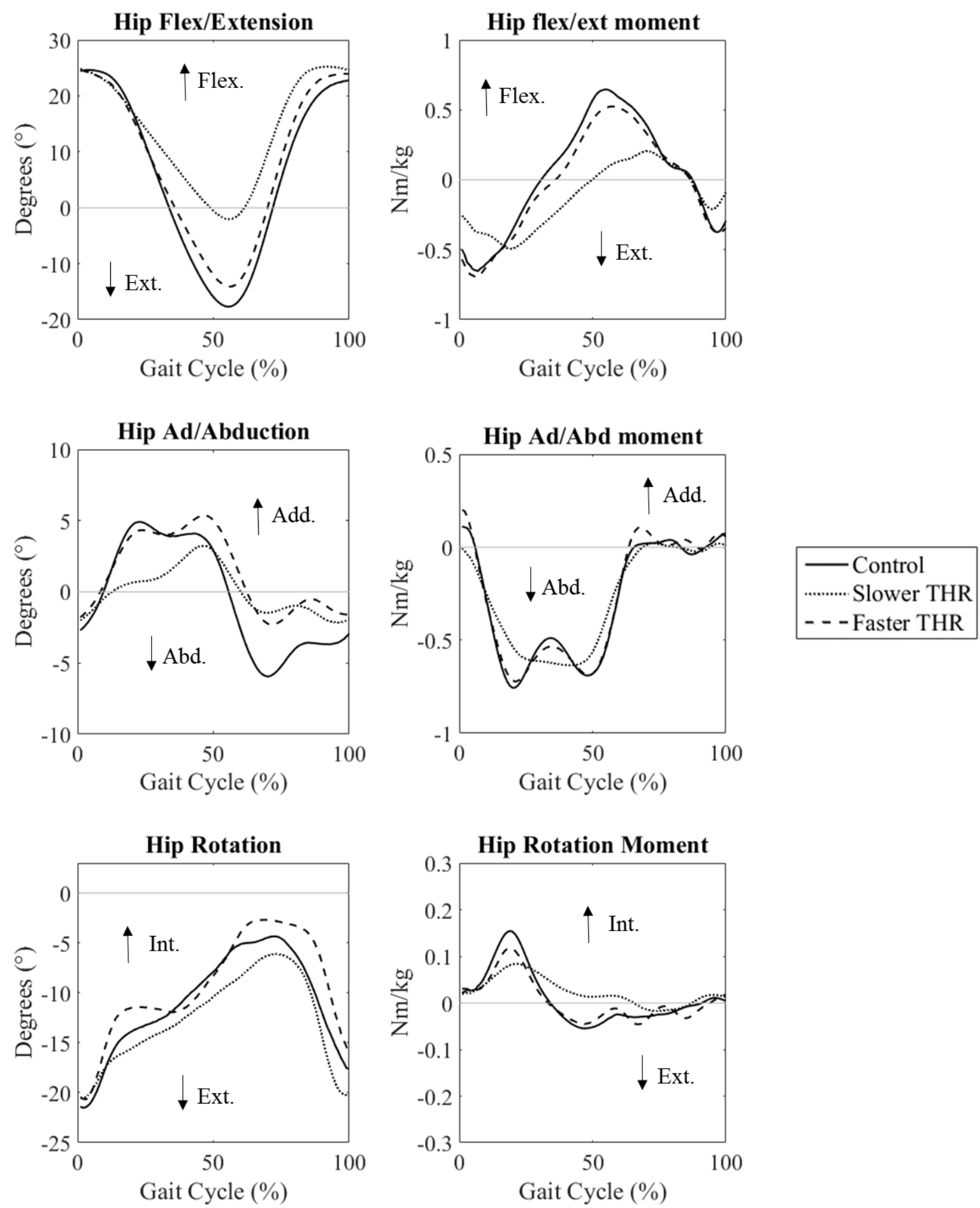

2 Figure 2: Inverse kinematics and dynamics results for control (solid line), slower THR (dotted),

3 and faster THR (dashed). See Table 2 (kinematics) and Table 3 (moments) for detailed numerical

4 data and statistical testing results. 


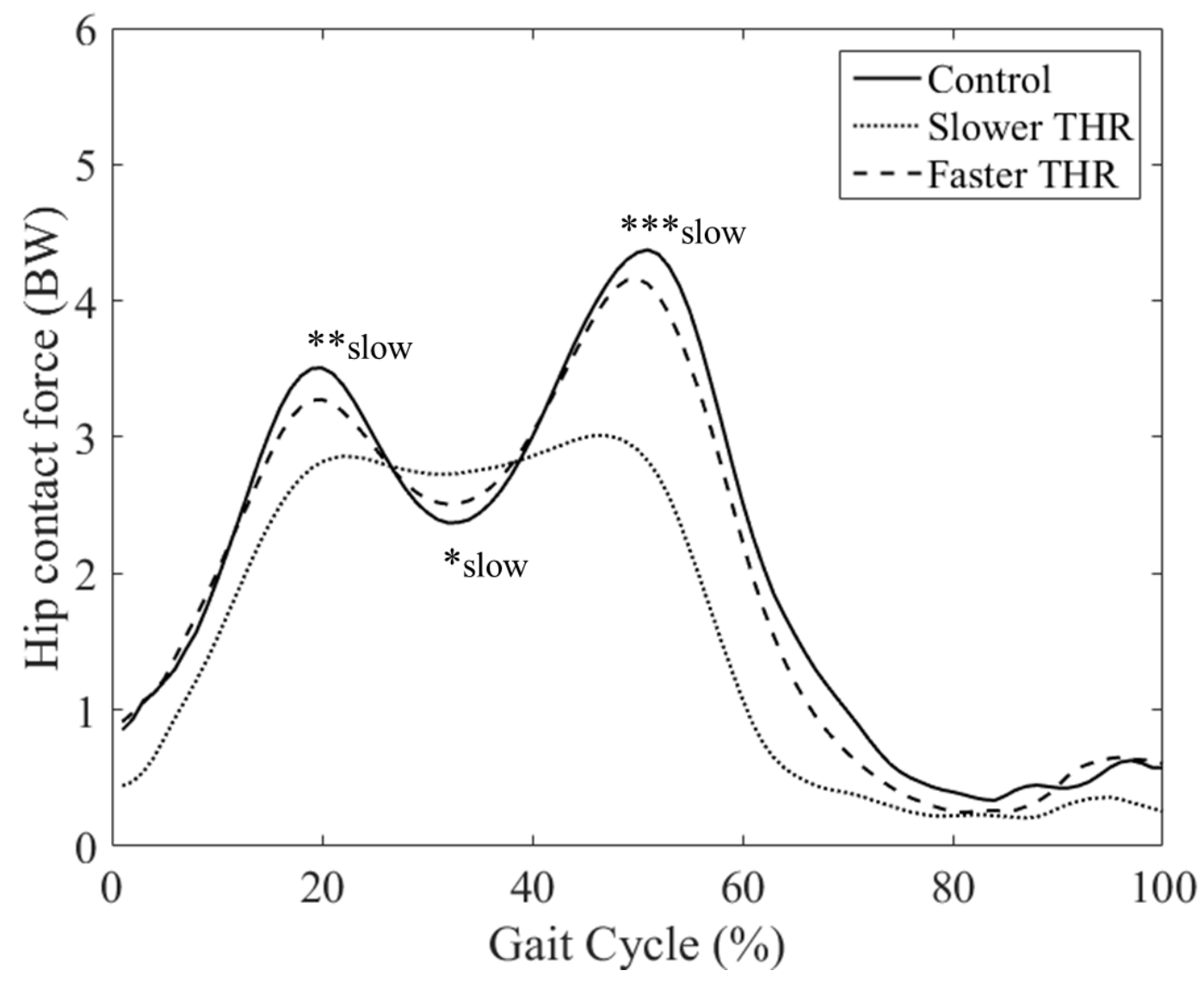

2 Figure 3: Hip joint contact forces over one gait cycle for slower and faster THR patients compared

3 to elderly control subjects. There were no statistical differences between the control and faster THR

4 groups at any of the three points analysed. Asterisks denote difference $(* * *=\mathrm{p}<0.001, * *=\mathrm{p}<0.01$

5 and $*=\mathrm{p}<0.05$ ) between controls and speed stratified groups only and are followed by 'slow' for

6 difference between slower and control subjects and 'fast' for differences between faster and control

7 subjects. 

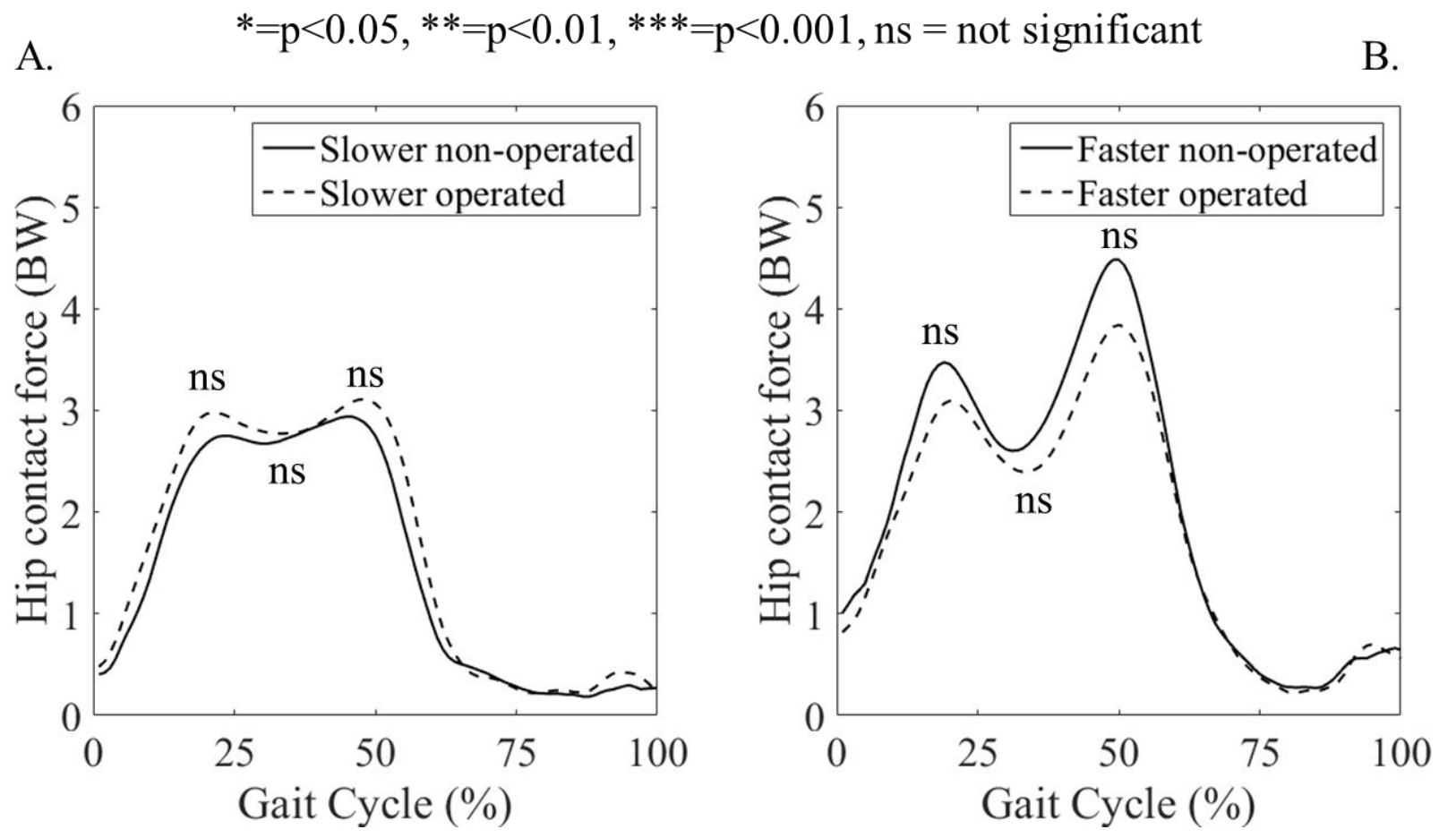

2 Figure 4: Comparison of operated and non-operated HCFs for slower (A) and faster (B) groups.

3 'ns' refers to differences that were not significant. 
Slower
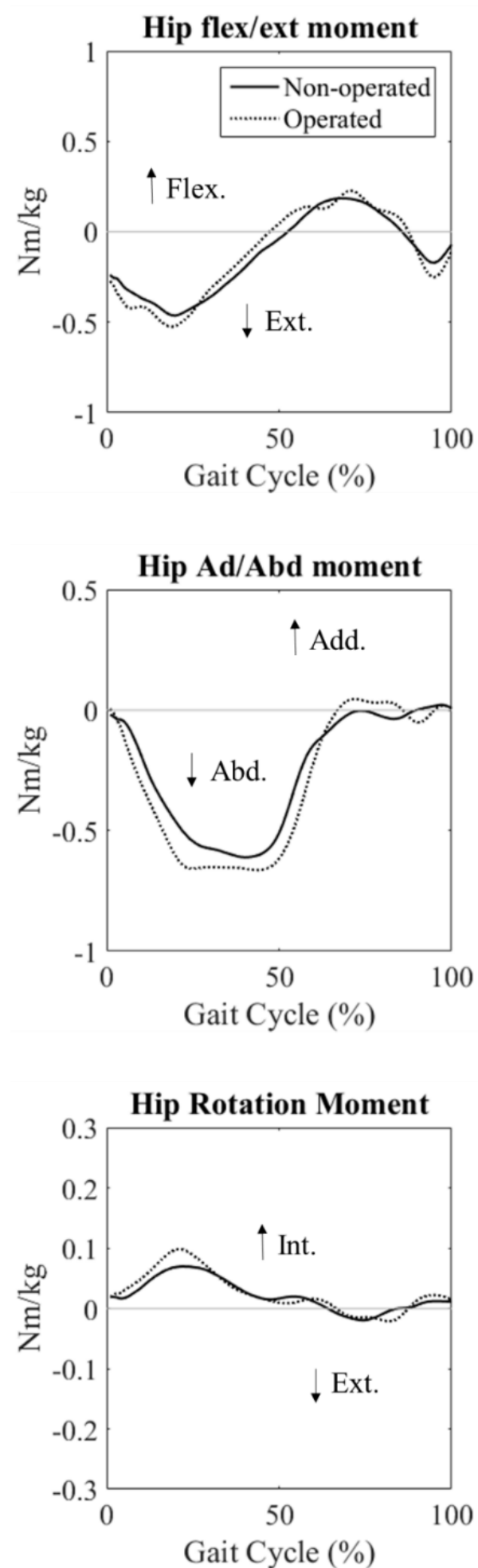

Faster
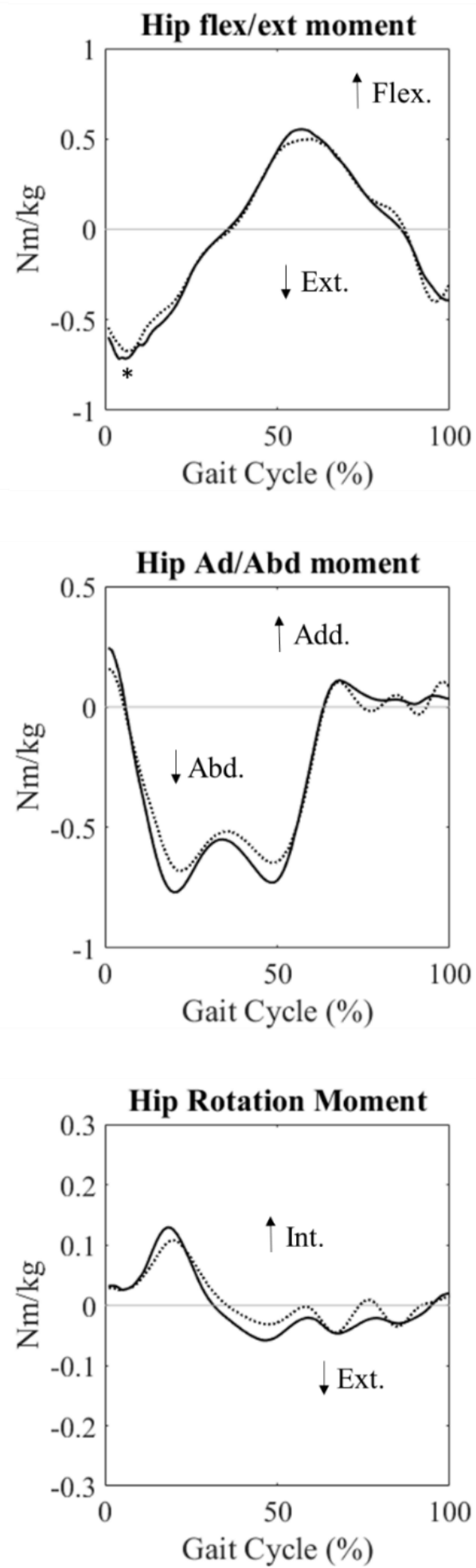

Figure 5: Comparison of moments between operated and non-operated limbs. Maximum hip extension moment in faster THR patients was the only peak with a statistical difference $(\mathrm{p}<0.05)$

5 between operated and non-operated hips. 